\title{
Development of Salbutamol Sulphate Sustained Release Pellets Using Acrylic Polymer and Polyvinyl Acetate Polymer and Evaluation of In vitro Release Kinetics
}

\author{
Saki Sultana, Ishtiaq Ahmed, Muhammad R. Islam and Md. Habibur Rahman \\ Department of Pharmaceutical Technology, Faculty of Pharmacy, University of Dhaka, \\ Dhaka-1000, Bangladesh
}

\begin{abstract}
The nuclei of sustained-release pellets of salbutamol sulphate were prepared using extrusionspheronization technique followed by coating with the aqueous dispersion of methacrylic acid esters (Eudragit RS $^{\circledR}$ $30 \mathrm{D})$ and commercial aqueous polyvinyl acetate dispersion (30\% dispersion) (Kollicoat $\left.\mathrm{SR}^{\circledR} 30 \mathrm{D}\right)$. The coating polymers were applied to obtain a theoretical polymer load of $5 \%, 10 \%, 15 \%, 20 \% \& 25 \%(\mathrm{w} / \mathrm{w})$ on the nuclei. Invitro dissolution studies of the coated pellets were performed in a USP paddle apparatus (type-2). Dissolution media was distilled water $(500 \mathrm{ml})$, paddle speed was $50 \mathrm{rpm}$ and it was preformed for 8 hours at $37^{\circ} \mathrm{C}\left( \pm 0.5^{\circ} \mathrm{C}\right)$ temperature. Scanning Electron Micrographs (SEMs) of the nuclei \& coated pellets were taken to study their surface morphology. The kinetics of the dissolution process was determined by analyzing the dissolution data using zeroorder, first order, Higuchi and Korsmeyer equations. The kinetic modeling of the dissolution profiles revealed that drug release mechanism ranged from diffusion controlled or Fickian transport to anomalous type or non-Fickian transport. $\mathrm{T}_{50 \%}$ (MDT) and $\mathrm{T}_{90 \%}$ values were calculated for each formulation. The higher MDT values were obtained with Eudragit ${ }^{\circledR}$ RS 30D where as Kollicoat ${ }^{\circledR}$ SR 30D showed comparatively low MDT values. MDT values were also increased with increasing polymer load on the nuclei.
\end{abstract}

Key words: Salbutamol sulphate, Pellet, Aqueous dispersion, Eudragit ${ }^{\circledR}$ RS 30 D, Kollicoat ${ }^{\circledR}$ SR 30D, Extrusion spheronization, MDT.

\section{INTRODUCTION}

Oral modified drug delivery systems can be classified into two broad groups: Single Unit Dosage forms (SUDFs) and Multiple Unit Dosage forms (MUDFs), such as granules, pellets, or mini tablets. The concept of MUDFs was initially introduced in 1950s. The production of MUDFs is a common strategy to control the release of drug as shown by the reproducibility of the release profiles when compared to the ones obtained with SUDFs ${ }^{1}$. Among the various approaches of MUDFs, popularity and attention to sustained release pharmaceutical pellets

Correspondence to:

Md. Habibur Rahman

Tel: +880-(0)2-9661900-73 Extn.8175; Fax: +880-(0)2-8615583

Email: rashed1505@yahoo.com

Dhaka Univ. J. Pharm. Sci. 9(2): 109-118, 2010 (December) are rapidly increasing. Pellet has been used to describe a variety of systematically produced, geometrically defined agglomerate obtained from diverse starting materials utilizing different processing conditions. Their size usually ranges from $0.5 \mathrm{~mm}$ to $1.5 \mathrm{~mm}$ which are intended mostly for oral administration ${ }^{2-4}$. Pellets offer several manufacturing and biopharmaceutic advantages. Due to free flowing character of pellets they are packed easily without any difficulties and give flexibility in design and development of a uniform solid dosage form (uniform weighed tablets and capsules) ${ }^{5-6}$. The spherical shape and low surface area to volume ratio of pellets help in uniform film coating ${ }^{7}$. Two or more drugs can be formulated in a single dosage form, chemically compatible or incompatible, at the same 
site or different sites in the gastrointestinal tract. Different release rates of the same drug can be supplied in a single dosage form ${ }^{8}$. Pellets are also less affected by gastric emptying. ${ }^{9}$ After administration, the coated pellets spread uniformly throughout the gastrointestinal tract and high local concentrations of drug can be avoided, along with the risk of localized toxic reaction.

Sustained release pharmaceutical pellets are usually prepared by preparing the nuclei with the drug and then coating the nuclei with different release retarding polymers at various coating thickness by judicious selection of process parameters. ${ }^{10-16}$ Globulation, balling, compression, compaction and drug layering etc. are some common pelletization techniques used in pharmaceutical industry. Among the compaction techniques extrusion and spheronization is the most widely used method which is a multiple-step compaction process. ${ }^{1}$

Aqueous film-coating dispersions generally consist of polymeric colloidal particles, a plasticizer, a pigment, and an anti-adherent agent. ${ }^{17}$ In the current experiment, drug containing cores were coated with the aqueous polymeric dispersions of Eudragit ${ }^{\circledR} \mathrm{RS}$ $30 \mathrm{D}$ and Kollicoat ${ }^{\circledR}$ SR 30D. Both of them were in $30 \%$ dispersion form. Eudragit ${ }^{\circledR} R S 30 \mathrm{D}$ is the aqueous dispersion of copolymers of acrylic acids and methacrylic acid esters with high content of quarternary ammonium groups. Kollicoat ${ }^{\circledR}$ SR 30D, an aqueous dispersion composed of $27 \%$ polyvinyl acetate (PVAc), $2.5 \%$ povidone, and $0.3 \%$ sodium lauryl sulfate, was introduced by BASF AG (Ludwigshafen, Germany). ${ }^{18,19}$ With adequate plasticizing, the formed PVAc film has been shown to possess unique physical and mechanical properties such as enormous flexibility, rendering the filmcoated pellets compressible without rupture. ${ }^{20}$ Both the polymers release drugs in a $\mathrm{pH}$ independent fashion. ${ }^{19,21-23}$

Salbutamol sulphate (a highly water soluble drug) was used in this experiment as a model drug which is a short-acting $\beta_{2}$-adrenergic receptor agonist used for the relief of bronchospasm in conditions such as asthma and chronic obstructive pulmonary disease. Salbutamol was the first selective $\mathrm{B}_{2}$-receptor agonist to be marketed - in 1968. It was first sold by Allen \& Hanburys under the brand name Ventolin. Chemically the drug is (RS)-4-[2-(tertbutylamino)-1-hydroxyethyl]-2-(hydroxymethyl) phenol having a molecular mass of 239.311. The half life of the drug is 1.6 hours and it undergoes hepatic metabolism in human body. Due to short elimination half life of the drug, frequent dosing is necessary to maintain therapeutic plasma levels. Therefore a controlled release preparation of the drug may improve patient compliance, minimize side effects and be valuable in the treatment of nocturnal asthma by extending drug action throughout the night.

\section{MATERIALS AND METHODS}

Materials that are used throughout the experiment are salbutamol sulphate (BDR Pharmaceuticals Ltd., India), lactose monohydrate (Hilmer Ingredients, USA), Microrystalline cellulose (MCC, Ming Tai Chemical co. Ltd., Taiwan), maize starch (Cerestar, Netherlands), HPMC 5cps (Colorcon, USA), Eudragit ${ }^{\circledR}$ RS 30 D (Evonic Rohm GmbH, Germany), Kollicoat ${ }^{\circledR}$ SR 30 D(BASF, Germany), purified talc (Asian Mineral Resources Co. Ltd., Thailand), triethyl citrate (Morflex Inc., USA). All the other chemicals used were of analytical grade.

Preparation of nuclei. The non-pariel seeds (NPS) containing salbutamol sulphate were manufactured using extrusion-spheronization technology. At first the required amount of drug (salbutamol sulphate) and the diluents (lactose, maize starch, and microcrystalline cellulose) were sieved through 80 mesh stainless steel screen and mixed properly in a laboratory scale planetary mixer (Umang Pharmatech Pvt. Ltd., India) to prepare a homogenous powder dispersion. The dry mix was then wet granulated using a binder solution (HPMC $5 \mathrm{cps}$ in purified water) in the same mixer to produce a plastic wet mass having sufficient binding affinity. The wet mass was passed through the screen of a fully automated extruder (Caleva, UK. rpm 40 and 1 
$\mathrm{mm}$ screen) to form rod shaped extrudes of uniform diameter. Then these extrudes were charged into spheronizer (Caleva, UK) and rounded off (rpm 600, $2 \mathrm{~mm}$ plate, 1 minute) to prepare the spheres of salbutamol sulphate core. The core pellets were then dried in a tray dryer (Indo-German PVT Ltd., India) at $60^{\circ} \mathrm{C}$ temperature for 3 hours to achieve the desired moisture content. The pellets were then screened using ASTM 28 mesh $(600 \mu \mathrm{m})$ followed by ASTM 16 mesh $(920 \mu \mathrm{m})$ to achieve the targeted size distribution $(600-920 \mu \mathrm{m})$.
Coating of nuclei with Eudragit ${ }^{\circledR}$ RS 30 D. To prepare the spray suspension, talc and triethyl citrate was suspended in the purified water and the suspension was poured into Eudragit ${ }^{\circledR}$ RS 30 D with continuous gentle stirring (Table 1). $300 \mathrm{~g}$ quantities of nuclei were coated using fluid bed coater (Labcoater; Umang Pharmatech, India) to different thickness equivalent to theoretical polymer load of $5 \%, 10 \%, 15 \%, 20 \% \& 25 \% \mathrm{w} / \mathrm{w}$ and samples were drawn from the Labcoater after each level of polymer load. The coated samples were then dried in the Labcoater for additional 3 hours at $60^{\circ} \mathrm{C}$ temperature. The process parameters are shown in Table 2 .

Table 1. Composition of salbutamol sulphate pellets (Core \& coat formula).

\begin{tabular}{|c|c|c|}
\hline \multicolumn{3}{|c|}{ Formula for Nuclei } \\
\hline Materials & \multicolumn{2}{|c|}{ Amount $(\mathrm{g})$} \\
\hline Salbutamol sulphate & \multicolumn{2}{|c|}{288.00} \\
\hline Lactose monohydrate & \multicolumn{2}{|c|}{1200.00} \\
\hline Microcrystalline cellulose (Avicel PH 101) & \multicolumn{2}{|c|}{662.00} \\
\hline Hypromellose (HPMC $5 \mathrm{cps}$ ) & \multicolumn{2}{|c|}{50.00} \\
\hline Purified water* & \multicolumn{2}{|c|}{300.00} \\
\hline \multicolumn{3}{|c|}{ Formula for coating } \\
\hline \multirow[b]{2}{*}{ Materials } & \multicolumn{2}{|c|}{ Amount $(\mathrm{g})$} \\
\hline & $\begin{array}{l}\text { Pellets coated with } \\
\text { Eudragit }^{\circledR} \text { RS 30D }\end{array}$ & $\begin{array}{l}\text { Pellets coated with } \\
\text { Kollicoat }{ }^{\mathbb{B}} \text { SR 30D }\end{array}$ \\
\hline Eudragit $^{(\mathbb{R}}$ RS 30D & 250.00 & - \\
\hline Kollicoat $^{\mathbb{R}}$ SR 30D & - & 250.00 \\
\hline Talc & 12.50 & 12.50 \\
\hline Triethyl Citrate & 12.50 & 12.50 \\
\hline Purified water* & 225.00 & 225.00 \\
\hline
\end{tabular}

*less than $0.2 \%$ will be present in final preparation

Table 2. Machine parameters set up during coating.

\begin{tabular}{ll}
\hline Machine & Labcoater (Wurster, Umang Pharmatech Ltd.) \\
\hline Batch size & $300 \mathrm{~g}$ \\
Method & Bottom-spray (Wurster) \\
Inlet air temperature & $50-55^{\circ} \mathrm{C}$ \\
Outlet air temperature & $29-32^{\circ} \mathrm{C}$ \\
Product temperature & $35-40^{\circ} \mathrm{C}$ \\
Chamber humidity & $55 \%$ \\
Air flow & $90 \mathrm{~m}^{3} / \mathrm{h}$ \\
Nozzle diameter & $1.2 \mathrm{~mm}$ \\
Spraying rate (approx.) & $3.0 \mathrm{~g} / \mathrm{min}$ \\
Atomizing pressure & $1.2 \mathrm{bar}$ \\
Drying temp. & $60^{\circ} \mathrm{C}$ \\
Drying time & $3 \mathrm{hours}$ \\
\hline
\end{tabular}

Coating of nuclei with Kollicoat ${ }^{\circledR}$ SR 30 D. The coating suspension was prepared with Kollicoat ${ }^{\circledR}$ SR $30 \mathrm{D}$, triethyl citrate as plasticizer and talc as antiadherent and final volume was reached with purified water (Table 1). For coating, $300 \mathrm{~g}$ nuclei were coated using fluid bed coater (Labcoater; Umang Pharmatech, India) with Kollicoat $^{\mathbb{B}}$ SR 30 D containing coating suspension to different thickness 
equivalent to theoretical polymer load of $5 \%, 10 \%$, $15 \%, 20 \%$, \& $25 \% \mathrm{w} / \mathrm{w}$. Samples were drawn from the Labcoater after each level of polymer load. The coated samples were then dried in the Labcoater for additional 3 hours at $60^{\circ} \mathrm{C}$ temperature. The process parameters are shown in Table 2.

Physical characterization of coated pellets. Loss on drying (LOD) was determined on $1.0 \mathrm{~g}$ pellets at $60^{\circ} \mathrm{C}$ under vacuum for 4 hours. Resistance to abrasion was determined using a Roche TAR 10 friabilator (Erweka, Ensenstam, Germany). $10 \mathrm{~g}$ of drug-loaded pellets (nuclei) were mixed with $25 \mathrm{~g}$ glass spheres $(5 \mu \mathrm{m}$ in diameter) and uniformly tumbled for 10 minutes at $25 \mathrm{rpm}$. Weight loss from the pellets was measured afterwards. Shape and surface morphology of the core and the coated pellets (cured \& uncured) were examined by using Scanning Electron Microscope (Hitachi, Model: S-3400 N, Japan). Scanning Electron Micrographs (SEMs) of the samples having different magnifications are presented in Figure 5 \& 6 .

In-vitro dissolution study. The dissolution of salbutamol sulphate sustained release pellets was studied by an Erweka (Germany) dissolution tester using USP apparatus 2 (Paddle method). Here $500 \mathrm{ml}$ distilled water was used as dissolution medium as the release kinetics of salbutamol sulphate sustained release pellets was found to be independent of the dissolution medium. ${ }^{24}$ Salbutamol sulphate sustained release pellets equivalent to $8 \mathrm{mg}$ salbutamol sulphate was placed into the vessels of the dissolution apparatus at $37 \pm 0.5^{\circ} \mathrm{C}$. Paddle was immersed in media to a distance of $2.5 \pm 0.2 \mathrm{~cm}$ between the paddle and bottom of the vessel. At the end of $1^{\text {st }}$ hour, $5 \mathrm{ml}$ samples were withdrawn from each vessel and filtered through Whatman filter paper no. 42. The withdrawn quantity of samples was replaced by fresh dissolution medium to maintain the constant volume of dissolution medium. The absorbance of filtered samples was measured at $276 \mathrm{~nm}$ by a UV-visible spectrophotometer (Shimadzu, Japan) using distilled water as blank. This operation was continued for another 7 hours.

\section{RESULTS AND DISCUSSION}

The color of the drug loaded pellets was found almost white to off-white and round shaped. No significant difference in color was found between two types of coated pellets. As the nuclei were prepared by wet massing, little amount of moisture was expected. The LOD of nuclei was found $0.18 \%$ which was acceptable. Over dried pellets become fragile and over moistened pellets have the tendency to stick. So the balance between moisture and friability is critical. The friability of nuclei was $0.22 \%$ which was very well within the requirement (below 1\%). The friability of the pellets was further reduced after coating with the polymers. Before coating the pellets size distribution was $600 \mu-920 \mu$ and after coating it was slightly increased $(700 \mu$ $1150 \mu$ ). In addition to spherical shape and smooth surface, a narrow size distribution of pellets is prerequisite for acceptable film coating. The size distribution affects both the performance of the coating and the release rate of the drug. ${ }^{12,14,25}$ The pellets coated with Kollicoat ${ }^{\circledR}$ SR 30D showed some degree of surface roughness but pellets coated by Eudragit $^{\circledR}$ RS 30D produced a comparatively smoother surface.

The nature of the two polymers markedly affected drug release rate and release mechanism from the pellets. It was evident from Figure 1 that drug release rate was decreasing with increasing polymer load in case of both polymers. It was also observed that release retarding property of Eudragit ${ }^{\circledR}$ RS 30D was higher in comparison to Kollicoat ${ }^{\mathbb{B}}$ SR 30D. Almost equal amount of Eudragit ${ }^{\circledR}$ RS 30D sustained the drug release for longer period of time than Kollicoat $^{\mathbb{B}}$ SR 30D. This is mainly due to relative hydrophilic and hydrophobic nature of the polymer film. More hydrophobic of the coating polymer, more the drug release retarding property. The ' $n$ ' values (release exponent) from KorsmeyerPeppas equation for Eudragit ${ }^{\circledR}$ RS 30D were found to be variable at various levels of polymer load. It was found that the drug was released mainly through erosion of the polymer chain from the pellets loaded up to $10 \%$ with Eudragit ${ }^{\circledR}$ RS 30D. The release 
exponent values were above 0.85 (Table 3 ) up to this level of polymer load that indicated super case-II transport mechanism. But when the polymer load was increased drug release mechanism was changed from super case-II transport to non-Fickian transport. The release exponent values found at $15 \%, 20 \%$ and $25 \%$ polymer load of Eudragit ${ }^{\circledR}$ RS 30D (Table 3) indicated anomalous transport mechanism of drug (as release exponent values were in between 0.430 \& 0.850). That means drug release followed the combined process of erosion of the polymer chain and diffusion through the membrane where diffusion process predominated.

Table 3. Release kinetics of Salbutamol sulphate pellets

\begin{tabular}{ccccccccccc}
\hline & \multicolumn{9}{c}{ Coating load of Eudragit ${ }^{\circledR}$ RS 30D coated pellets } & \multicolumn{7}{c}{ Coating load of Kollicoat ${ }^{\circledR}$ SR 30D coated pellets } \\
\cline { 2 - 11 } & $5 \%$ & $10 \%$ & $15 \%$ & $20 \%$ & $25 \%$ & $5 \%$ & $10 \%$ & $15 \%$ & $20 \%$ & $25 \%$ \\
\hline $\begin{array}{c}\text { Zero order } \\
\mathrm{r}^{2}\end{array}$ & 0.97 & 0.95 & 0.99 & 0.96 & 0.98 & 0.92 & 0.95 & 0.99 & 0.95 & 0.96 \\
$\mathrm{~K}_{0}$ & 13.7 & 12.2 & 4.9 & 2.2 & 1.7 & 10.4 & 6.7 & 3.9 & 2.3 & 1.7 \\
First order & & & & & & & & & & \\
$\quad \mathrm{r}^{2}$ & 0.93 & 0.98 & 0.99 & 0.93 & 0.92 & 0.98 & 0.99 & 0.98 & 0.90 & 0.95 \\
$\mathrm{~K}_{1}$ & -0.24 & -0.12 & -0.03 & -0.009 & -0.007 & -0.12 & -0.04 & -0.02 & -0.01 & -0.008 \\
Korsmeyer & & & & & & & & & & \\
$\mathrm{r}^{2}$ & 0.99 & 0.96 & 0.98 & 0.96 & 0.92 & 0.99 & 0.99 & 0.99 & 0.92 & 0.99 \\
$\mathrm{n}$ & 1.02 & 1.07 & 0.73 & 0.59 & 0.52 & 0.437 & 0.701 & 1.01 & 0.977 & 0.997 \\
$\mathrm{~K}$ & -0.87 & -0.95 & -1.09 & -1.41 & -1.46 & -0.43 & -0.87 & -1.42 & -1.71 & -1.79 \\
Higuchi & & & & & & & & & & \\
$\mathrm{r}^{2}$ & 0.91 & 0.90 & 0.92 & 0.87 & 0.89 & 0.99 & 0.98 & 0.93 & 0.88 & 0.87 \\
$\mathrm{~K}_{\mathrm{H}}$ & -18.82 & -16.19 & -6.07 & -2.57 & -1.13 & 3.26 & -3.79 & -4.16 & -2.56 & -2.23 \\
MDT $\left(\mathrm{t}_{50 \%}\right)$ & 3.85 & 4.55 & 6.25 & 12.50 & 16.67 & 1.35 & 3.85 & 12.5 & 25.0 & 25.58 \\
$\left(\mathrm{t}_{90 \%}\right)$ & 6.67 & 7.13 & 27.54 & 195.81 & 692.56 & 7.56 & 15.69 & 22.65 & 48.56 & 49.86 \\
\hline
\end{tabular}

Another important observation in case of Eudragit $^{\circledR}$ RS 30D was that when polymer load was changed from $5 \%$ to $10 \%$, drug release rate was not changed much, but when it was changed from $10 \%$ to $15 \%$ drug release rate had been drastically fallen. Then further increase of polymer load did not change drug release rate in so significant extent. That means drug release rate and mechanism both were changed to a significant extent when polymer load was changed from 10 to $15 \%$. So this range of polymer loads $(10 \%-15 \%)$ may be considered as the critical range of polymer load in case of Eudragit ${ }^{\circledR}$ RS 30D. Unlike Eudragit $^{\circledR}$ RS 30D, Kollicoat ${ }^{\circledR}$ SR 30D showed a comparatively good degree of linearity of drug release rate with that of increasing polymer load (Figure 1). The release exponent values at 5\% and $10 \%$ polymer load of Kollicoat ${ }^{\circledR}$ SR 30D (Table 3) indicated non-Fickian transport mechanism of drug. Therefore drug was released by both diffusion and erosion mechanism, where diffusion process predominated. But, when the polymer load was increased the release exponent values were found to be above 0.85 (Table 3) that indicated super case -II transport mechanism of drug release. That means, at higher level of polymer load erosion of the polymer chain became the predominant drug release mechanism. The release mechanism of drug by anomalous process can be explained by the fact that polyvinyl acetate was a water insoluble polymer, so passage of aqueous dissolution medium through this polymeric membrane was controlled by presence of povidone (a soluble component) in the Kollicoat ${ }^{\mathbb{R}} \mathrm{SR}$ 30D coating suspension which leached out of the film forming a porous membrane. Through this porous membrane water entered into the core and drug was released slowly through diffusion process. But, at higher level of polymer load, the pores of the polymer membrane created by the soluble povidone was not enough to control the drug release. Therefore erosion of the polymer chain occured. Here one important point must be mentioned that selected 
plasticizer type and subsequent curing conditions play important roles in controlling drug release from such a system. ${ }^{26}$

In most of the cases it was revealed that the release kinetics of salbutamol sulphate from the coated pellets appeared to follow the mixed release kinetics of zero order $\left(r^{2}>0.95\right)$, first order $\left(r^{2}>0.90\right)$ as well as Higuchi's release kinetics $\left(\mathrm{r}^{2}>0.85\right)$ (Figure 1, 2, 3 and Table 3).
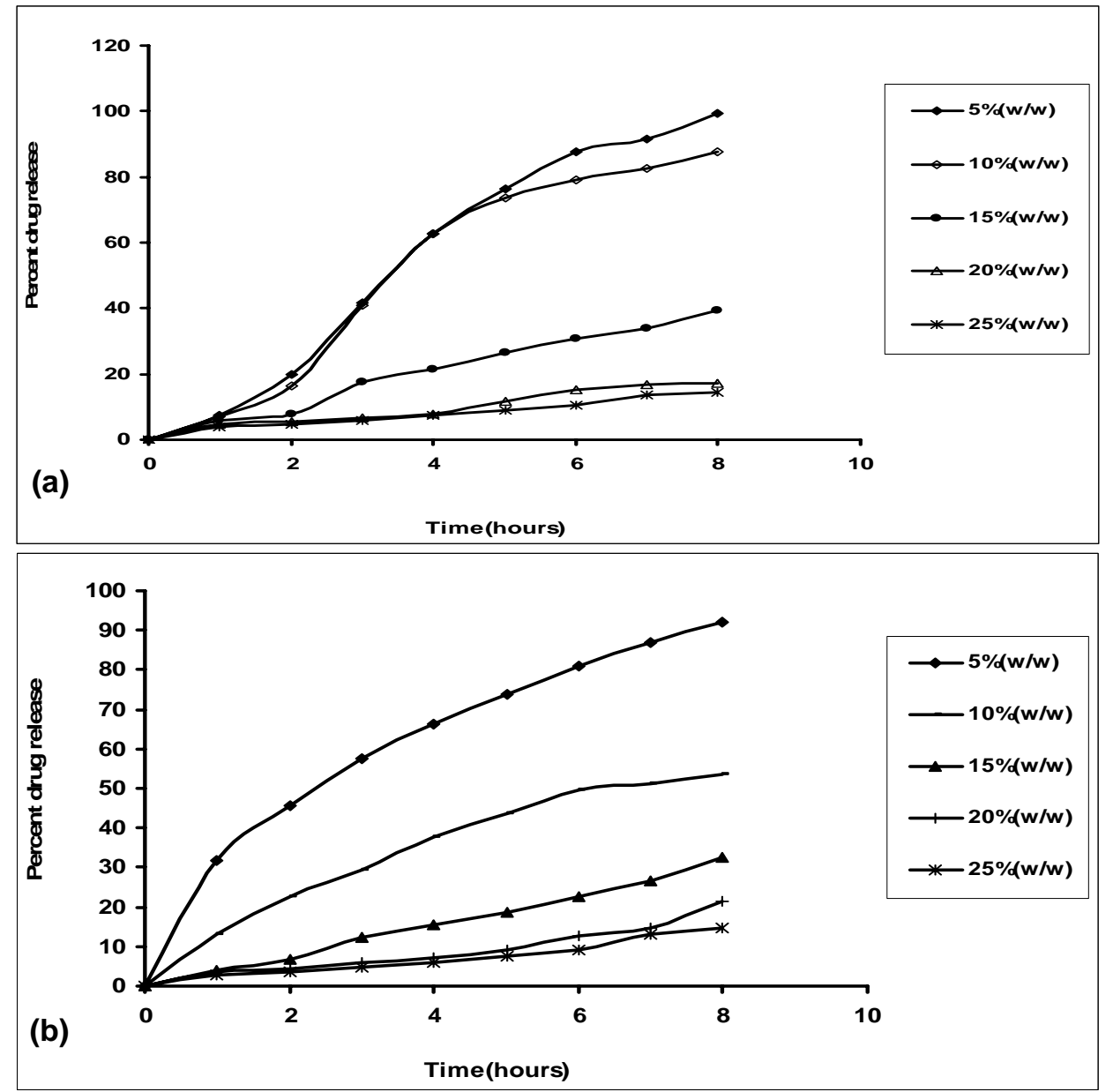

Figure 1. Zero order release profile of salbutamol sulphate from pellets coated with (a) Eudragit ${ }^{\circledR}$ RS 30D \& (b) Kollicoat ${ }^{\circledR}$ SR 30D

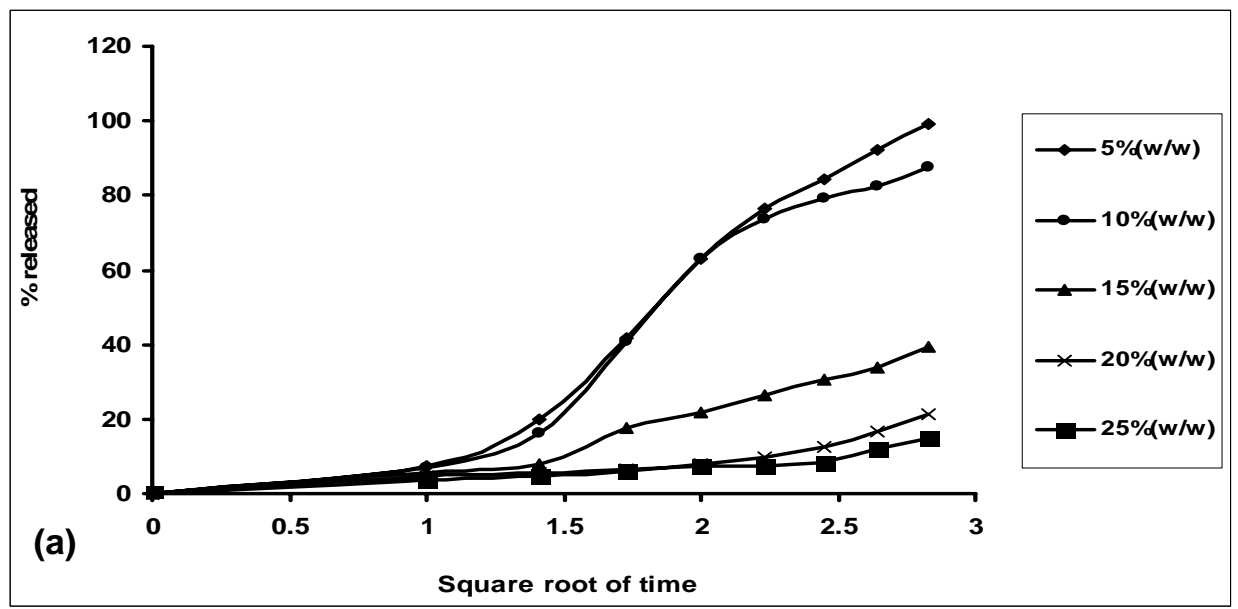




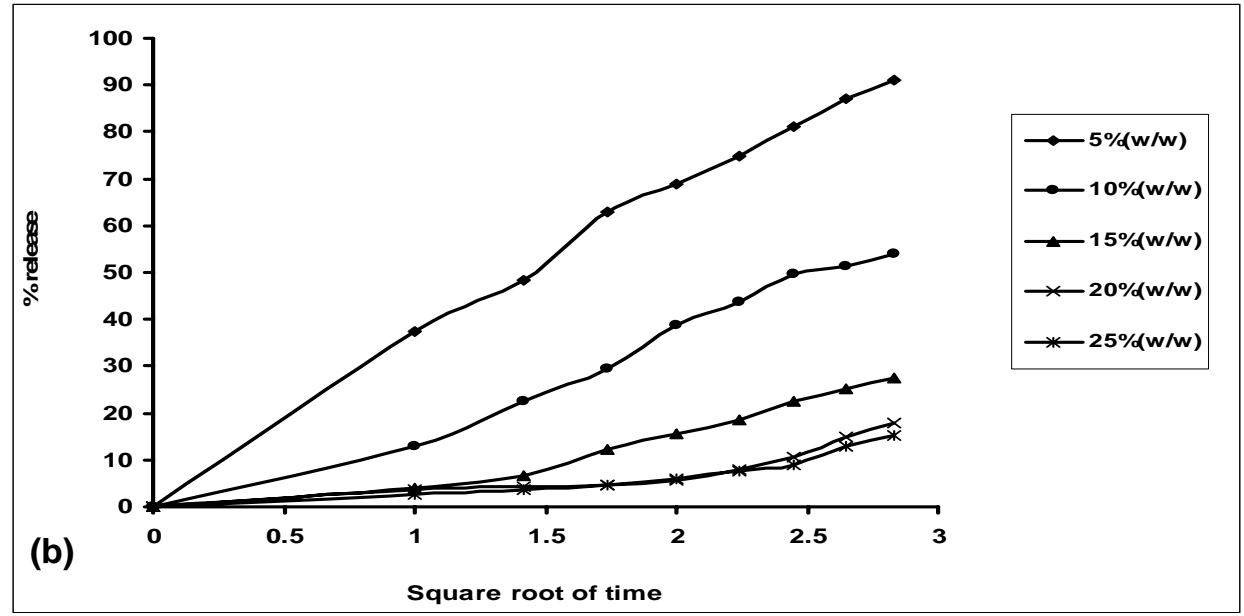

Figure 2. Higuchi release profile of salbutamol sulphate from pellets coated with (a) Eudragit ${ }^{\circledR}$ RS 30D \& (b) Kollicoat ${ }^{\circledR}$ SR 30D.
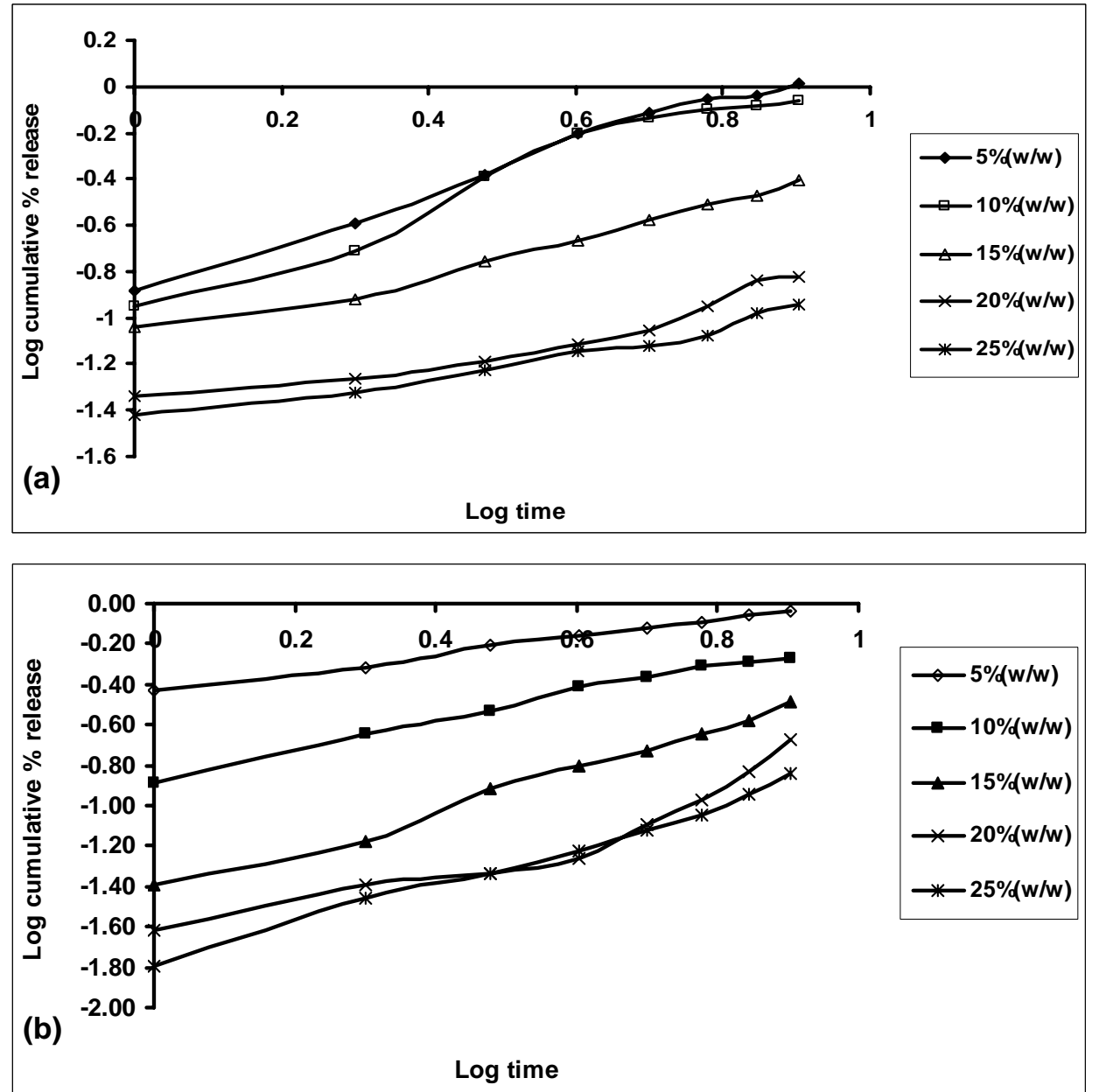

Figure 3. Korsmeyer release profile of salbutamol sulphate from pellets coated with (a) Eudragit ${ }^{\circledR}$ RS 30D \& (b) Kollicoat ${ }^{\circledR}$ SR 30D. 


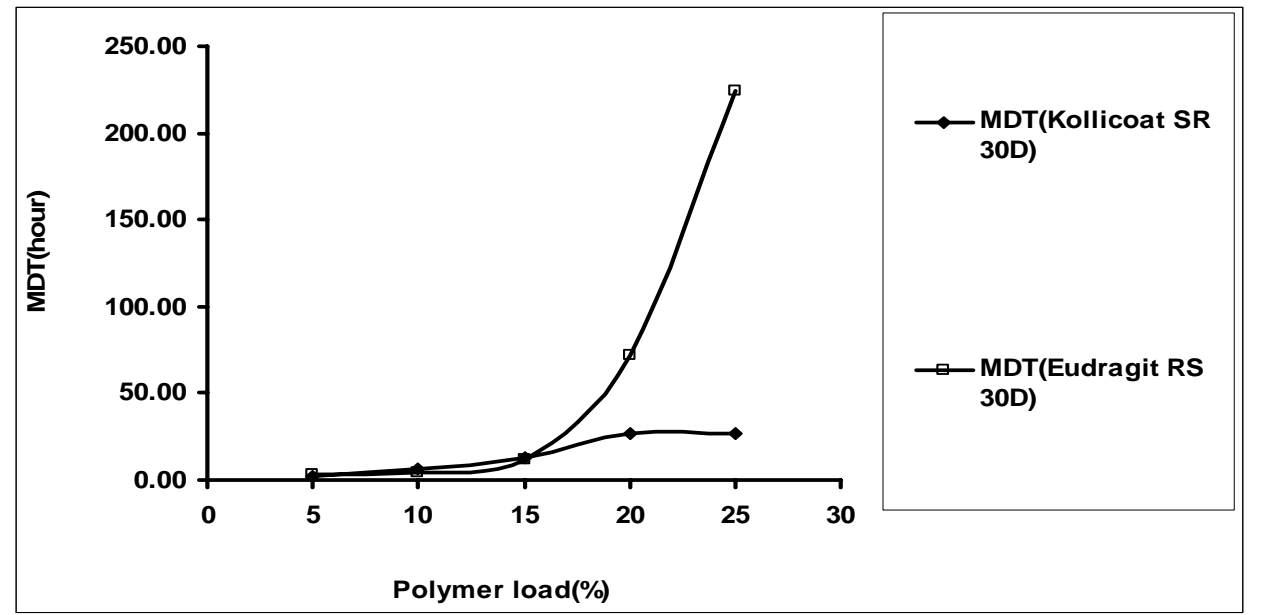

Figure 4. Effect of polymer load on mean dissolution time (MDT) of salbutamol sulphate sustained release pellets.

The release of salbutamol sulphate from the coated pellets was dependent not only on the nature of the polymer but also on the coating thickness of the polymer. It had been observed that the formulation that contained higher percentage of polymer, released the drug at slower rate i.e. extended the release of drug for longer period. The extension of release was directly related to percentage of polymer applied to the nuclei. Drug release was controlled by penetration of water through the gel layer around the pellets when they came into contact of dissolution medium. High amount of polymer loading caused the formation of an extensive gel layer through which it became difficult for the drug to be released into the dissolution medium. Extensive swelling of polymers increased the thickness of the gel layer around the pellets and consecutively increased the path length of diffusion. Again, increasing amount of polymer load led to decrease the porosity of the film coating resulting in retardation of drug release. Mean dissolution time (MDT) values were determined to characterize the drug release rate from the coated pellets and the retaining efficiency of the polymers (Table 3). A higher value of MDT indicates a higher drug retaining ability of the polymer and vice versa. The mean dissolution time (MDT) of PVA based coating increased almost linearly $\left(\mathrm{r}^{2}=0.93\right)$ with increasing polymer load (Figure 2) but the acrylate coated pellets acted in a different way. In case of acrylate polymer, the regression co-efficient value was found 0.74 when we plotted MDT values against polymer loads. From the values of $t_{90 \%}$ (Table 2 ), it was evident that pellets coated with Eudragit ${ }^{\mathbb{R}}$ RS 30D released $90 \%$ drug at about 27 hours when polymer load was $15 \%$, whereas, Kollicoat ${ }^{\circledR}$ SR 30D released $90 \%$ drug within 22 hours at $15 \%$ coating load. So, both of these polymers can be used for preparation of once daily dosage forms of salbutamol sulphate by carefully controlling the coating thickness.

From the surface morphology obtained from SEMs of the coated pellets, it was also revealed that Eudragit $^{\mathbb{R}}$ RS 30D produced a dense compact film (Figure 5) which accounted for its lower release profile. SEMs of the pellets coated with Kollicoat ${ }^{\circledR}$ SR 30D exhibited smooth but less dense films with more cracks (Figure 6). That's why it caused a higher release. 

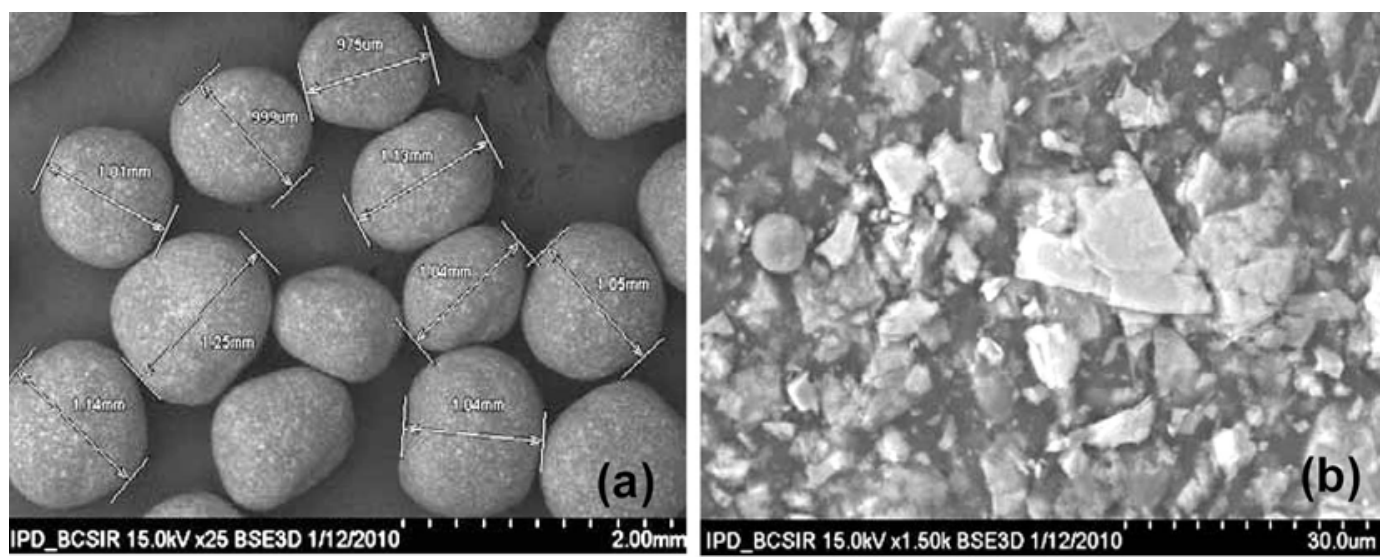

Figure 5. Scanning Electron Micrographs of Salbutamol sulphate sustained release pellets coated with Eudragit ${ }^{\circledR}$ RS 30 (polymer load $15 \%$ w/w) : (a) at X-25; (b) at X-1500

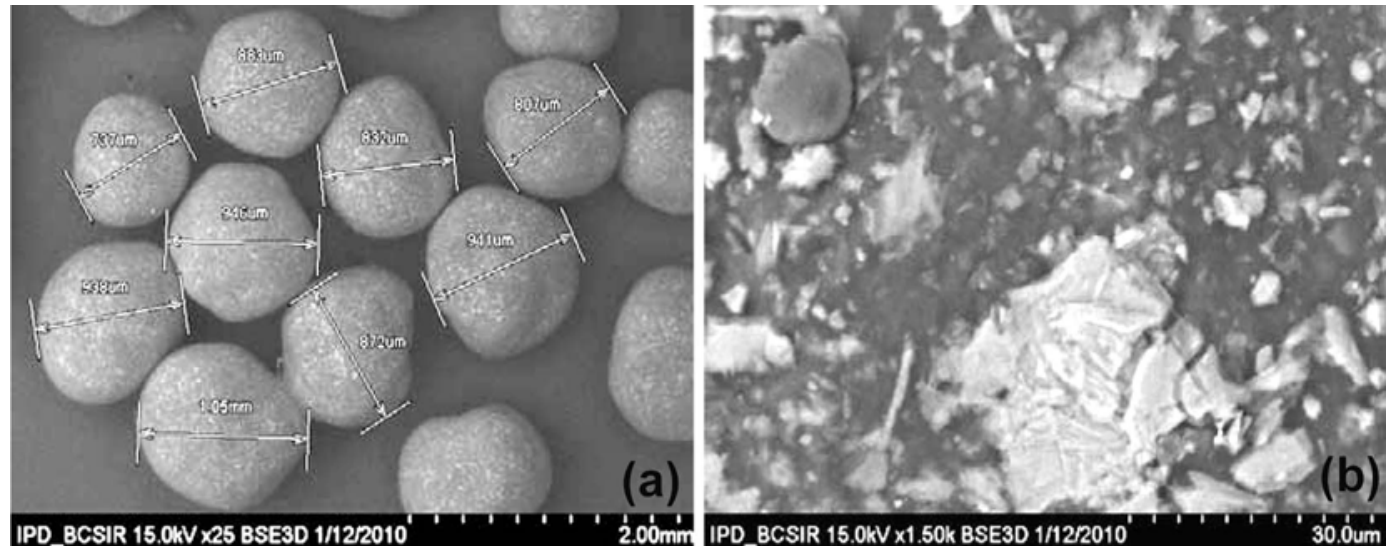

Figure 6. Scanning Electron Micrographs of salbutamol sulphate sustained release pellets coated with Kollicoat ${ }^{\circledR}$ SR 30D (polymer load $15 \% \mathrm{w} / \mathrm{w}):$ (a) at X-25; (b) at X-1500

\section{CONCLUSION}

Nuclei containing salbutamol sulphate prepared by extrusion-spheronization technique was successfully coated in Wurster column (bottom spray fluid bed coating system) with Eudragit ${ }^{\circledR}$ RS 30 D and Kollicoat ${ }^{\circledR}$ SR 30 D using a fixed amount of plasticizer, triethyl citrate (TEC). The coated pellets were spherical in nature and showed a good sustained release activity for up to 8 hours. Scanning Electron Micrographs (SEMs) of the coated pellets were taken to study surface morphology of the pellets. The release mechanisms were explored and explained with zero order, first order, Higuchi equation and Korsmeyer equation. Surface nature of the pellets and release behavior of the drug was changed due to change of polymer type and polymer thickness. Although both the polymers showed good sustaining effect of drug from the coated pellets but from the manufacturing point of view Kollicoat ${ }^{\circledR}$ SR 30D would be a better choice for preparing sustained release pellets of salbutamol sulphate as it showed more consistent and linear drug release profile.

\section{ACKNOWLEDGEMENTS}

The authors are thankful to Eskayef Bangladesh Ltd. (former SmithKline \& French, UK) for providing raw materials as well as manufacturing facilities. They also like to thank BASF and EVONIC for their generous gift of Kollicoat ${ }^{\circledR}$ SR 30D \& Eudragit $^{\mathbb{B}}$ RS $30 \mathrm{D}$ and also Bangladesh Council of Scientific and Industrial Research (BCSIR) for performing Scanning Electron Microscopic observation. 


\section{REFFERENCES}

1. Manivannan, R., Parthiban, K.G., Sandeep, G., Balasubramanium, A. and Senthikumar, N. 2010. Multiparticulate drug delivery systems: Pellet and pelletization technique. Drug Invention Today 2, 233-237.

2. Kristensen, H.G. and Schaefer, T. Granulation. 1987. A review of pharmaceutical wet granulation. Drug Dev. Ind. Pharm. 13, 803-872.

3. Ghebre-Sellassie, I. Pellets. 1989. A general overview. In Ghebre-Sellassie Pharmaceutical Pelletization Technology. I(ed), Marcel Dekker Inc., New York, USA, 37, 1-13.

4. Cox PH and Spanjers F. 1970. The preparation of sterile implants by compression. Pharm. Weekblad 105, 681-684.

5. Conine JW and Hadley HR. 1970. Small solid pharmaceutical spheres. Drug Cosmet. Ind 90, 38-41.

6. Ghebre-Sellassie I, Gordon R, Fawzi MB and Nebsitt RU. 1985. Evaluation of high speed pelletization process and equipment. Drug Dev. Ind. Pharm. 11, 1523-1541.

7. Vertommen, J., Rombaut, P. and Kinget, R. 1997. Shape and surface smoothness of pellets made in a rotary processor. Int. J. Pharm. 146, 21-29.

8. Wan LSC and Lai WF. 1991. Factors affecting drug release from drug coated granules prepared by fluidized-bed coating. Int. J. Pharm. 72, 163-174.

9. Shargel, L. and Andrew, B.C. 1941. Modified-release Drug Products and Targeted Drug Delivery System. In: Applied Biopharmaceutics and Pharmacokinetics. $3^{\text {rd }}$ Edn., Appleton \& Lange, USA, pp. 225-264

10. Mehta, A. M., Valazza, M. J. and Abele, S. E., 1986. Evaluation of fluid-bed processes for enteric coating systems. Pharm. Technol. 10, 46-56.

11. Ragnarsson, G., Sandberg, A., Johansson, M. O. and Sjogren, J., 1987. Development of a new controlled release metoprolol product. Drug Dev. Ind. Pharm. 13, 1495-1509.

12. Ragnarsson, G. and Johansson, M. O., 1988. Coated drug cores in multiple-unit preparations. Influence of particle size. Drug Dev. Ind. Pharm. 14, 2285-2297.

13. Bianchini, R. and Vecchio, C. 1989. Oral controlled release optimization of pellets prepared by extras ion-spheronization processing. II Farmaco. 44, 645-654.

14. Wesdyk, R., Joshi, Y. M., Jain, N. B., Morris, K. and Newman, A. 1990. The effect of size and mass on the film thickness of beads coated in fluidized bed equipment. Int. J. Pharm. 65, 69-76.
15. Marvola, M., Nykanen, P., Rautio, S., Isonen, N. and Autere, A. M. 1999. Enteric polymers as binders and coating materials in multiple-unit site-specific drug delivery systems. Eur. J. Pharm. Sci. 7, 259-267.

16. Umprayn, K., Chitropas, P. and Amarekajom, S. 1999. Development of terbutaline sulfate sustained-release coated pellets. Drug Dev. Ind. Pharm. 25, 477-491.

17. Chuanbin, Wu. and James, W.M. 2001. Influence of Ibuprofen as a Solid-State Plasticizer in Eudragit ${ }^{\circledR}$ RS 30 D on the Physicochemical Properties of Coated Beads. AAPS Pharm. Sci.Tech. 2, article 24.

18. Kollicoat SR 1999. 30 D., BASF Technical Bulletin, June $1999 ; 1-14$

19. Kolter, K. and Ruchatz, F. 1999. Kollicoat ${ }^{\circledR}$ SR 30D - A new sustained-release excipient. Proceed Int Symp Controlled Release Bioact Mater. 26, 6311.

20. Kibbe, H.A. 2000. Handbook of Pharmaceutical Excipients. $3^{\text {rd }}$ Edn., Americal Pharmaceutical Association and Pharmaceutical Press, pp. 599-601.

21. Dashevsky, A., Krause, A., Kolter, K. and Bodmeier, R. 2000. Compaction of pellets coated with a new aqueous polymer dispersion, Kollicoat ${ }^{\circledR}$ SR 30 D. AAPS PharmSci. 2000 AAPS Annual Meeting Supplement. 2(4). Available from:from http://www.aapspharmaceutica.com/scientific journals/pharmsci/am_abstract/2000/194.html.

22. Dashevsky, A., Wagner, K., Krause, A., Kolter, K. and Bodmeier, R. 1999. Coating of pellets with a new aqueous polymer dispersion, Kollicoat ${ }^{\circledR}$ SR 30 D. AAPS PharmSci. 1999 AAPS Annual Meeting Supplement. 1(4). Available from: http://www.aapspharmaceutica.com/scientific journals/ pharmsci/am_abstract/1999/1254.html.

23. Ruchatz, F., Kolter, K., Wittemer, S. and Frauenhofer, W. 1999. Kollidon ${ }^{\circledR}$ SR - A new excipient for sustained release matrices. Proceed Int Symp Controlled Release Bioact Mater. 26, 6312 .

24. Govender, T. and Dangor, C.M. Formulation and preparation of controlled pellets of salbutamol by the air suspension technique, Journal of Microencapsulation, 14(4), $444-455$

25. Hey, W.J. 1991. Effect of particle size and porosity on particle film coatings. Powder Tech. 65, 441-445

26. Shao, Z.J., Moralesi, L., Diaz, S. and Muhammadi, N.A. 2002. Drug Release From Kollicoat SR 30D-Coated Nonpareil Beads: Evaluation of Coating Level, Plasticizer Type, and Curing Condition, AAPS Pharm. Sci. Tech. 3 , article 15 . 